\title{
Host Plant and Leaf-Age Preference of Luprops tristis (Coleoptera: Tenebrionidae: Lagriinae: Lupropini): A Home Invading Nuisance Pest in Rubber Plantation Belts
}

\author{
Sabu K. Thomas, Mohandas Greeshma, and P. Aswathi \\ Post Graduate \& Research Department of Zoology, St. Joseph's College, Devagiri, Calicut, Kerala 673008, India \\ Correspondence should be addressed to Sabu K. Thomas, sabukthomas@gmail.com
}

Received 30 November 2010; Revised 27 January 2011; Accepted 9 February 2011

Academic Editor: Ai-Ping Liang

Copyright (C) 2012 Sabu K. Thomas et al. This is an open access article distributed under the Creative Commons Attribution License, which permits unrestricted use, distribution, and reproduction in any medium, provided the original work is properly cited.

\begin{abstract}
Massive seasonal invasion by the litter-dwelling beetle Luprops tristis, into residential buildings prior to monsoon rains, and their prolonged state of dormancy render them a very serious nuisance pest in rubber plantations in the Western Ghats in southern India. Feeding preferences of L. tristis towards leaf litter of seven trees co-occurring in rubber plantations, cashew (Anacardium occidentale), mango (Mangifera indica), jackfruit (Artocarpus heterophyllus), wild jack (Artocarpus hirsutus), cocoa (Theobroma cacao), cassia (Cassia fistula), sapota (Manilkara zapota) and rubber (Hevea brasiliensis) were analyzed with no-choice and multiple-choice leaf disc tests. Results showed that $L$. tristis is a generalist feeder with a defined pattern of preference, with the leaf litter of rubber being the most preferred followed by those of jackfruit and cocoa. Tender leaves were preferred over mature leaves except for cocoa and sapota. Equal preference towards tender and mature cocoa leaves, presence of patches of cocoa plantations and the scarce distribution of other host plants in rubber plantation belts leads to the proposal that in the absence of tender and mature rubber leaves, cocoa becomes the major host plant of L. tristis.
\end{abstract}

\section{Introduction}

Seasonal mass invasion of a litter-dwelling detritivorous beetle, Luprops tristis (Fabricius, 1801) (Coleoptera: Tenebrionidae: Lagriinae: Lupropini), numbering $0.5-4$ million per residential buildings prior to the onset of south west monsoon showers and subsequent aggregation in prolonged state of dormancy (Figure 1) render them a very serious nuisance pest in rubber plantation tracts in the Western Ghats in southern India [1]. Litter stands of rubber tree [Hevea brasiliensis, (Willd. ex Adr. De Jus) Müll. Arg. 1865] are the breeding and feeding habitat for $L$. tristis, with prematurely abscised leaves as the most preferred food resource, and a synchronized life cycle with the leaf phenology of rubber [2]. Their near absence in natural forests in contrast to exceptionally high abundance in rubber plantation litter established that rubber is the major host plant of the insect in the region [3-5]. Prevention of premature leaf fall of rubber may regulate the population build up of $L$. tristis in rubber plantations $[2,5]$. However, their presence in the leaf litter of trees namely, cashew (Anacardium occidentale, Linnaeus 1753), mango (Mangifera indica, Linnaeus 1753), jackfruit (Artocarpus heterophyllus, Lamarck 1789), wild jack (Artocarpus hirsutus, Lamarck 1789), cocoa (Theobroma cacao, Linnaeus 1753), cassia (Cassia fistula, Linnaeus 1753), and sapota (Manilkara zapota, Linnaeus 1753) co-occurring in rubber belts (personal observations, first author) led to the hypothesis that $L$. tristis may also feed on the leaf litter of these plants. Hence, it is essential to determine the feeding preference of $L$. tristis on these potential alternate host plants before attempting control by prevention of premature leaf fall in rubber plantations.

We propose that (i) L. tristis is a specialist feeder on rubber litter, and (ii) does not feed on the leaf litter of cashew, mango, jackfruit, wild jack, cocoa, cassia and sapota plants. Data generated is expected to contribute towards adoption of control strategies to prevent the possible spread of $L$. tristis to nonrubber plantation belts where plantations of potential host plants are prevalent. 


\section{Materials and Methods}

2.1. Study Organism. Luprops tristis (Fabricius, 1801) is generally regarded as an inconspicuous litter-dwelling detritivore but for their exceptionally high abundance in the rubber plantation litter stands across the moist south Western Ghats [1]. They are regionally referred to as "Mupli vandu" in Central and South Kerala and "Ola prani," "Ola chathan," or "Otteruma" in North Kerala in South India. No data exists on its ancestral host or about alternate host plants as it remained as a minor darkling beetle species of least importance, till it became a nuisance pest in residential buildings with the spread of rubber plantations in the moist western slopes of the Western Ghats during 1960-1970 period [6].

2.2. Host Plants. Plants with which L. tristis associated are as follows.

Mango (Mangifera indica: Anacardiaceae: Sapindales) is an evergreen tree, indigenous to the Indian subcontinent. Although an evergreen tree, large quantities of old leaves are shed during summer vegetative flush. The leaf-flushing period can have one to five flushing events with the whole canopy flushing in synchrony or in patches [7]. The most common native variety, Nattumavu, in the rubber belts was selected for the study.

Cashew (Anacardium occidentale: Anacardiaceae: Sapindales) was originally spread from Brazil by the Portuguese and is widely grown for cashew kernels popularly known as "cashew nuts" $[8,9]$. Although an evergreen tree, large quantities of old leaves are shed during presummer period prior to flowering (first author, personal observations).

Jackfruit (Artocarpus heterophyllus: Moraceae: Rosales) is a tall evergreen tree with spreading canopy. Although an evergreen tree, large quantities of old leaves are shed during summer vegetative flush. It is a common tree in the rubber belts as farmers use its fruits and seeds as a food item, leaves for fodder, and stem for timber [10].

Wild jack (Artocarpus hirsutus: Moraceae: Rosales) is a tall evergreen tree species that is endemic to the Western Ghats [11]. Large quantities of old leaves are shed during summer vegetative flush. It is a common tree in the rubber belts as planters allow a few trees to grow in the midst of rubber plantations due to the high commercial value of its wood and its taller canopy which do not interfere with growth of rubber plants.

Rubber (Hevea brasiliensis: Euphorbiaceae: Malpighiales) is a deciduous tree with a major annual leaf shedding during December, leaf flush in January, and flowering in February. Rubber plantations of about half a million hectares are present along the western slopes of the Western Ghats in the South Indian state of Kerala [2].

Cocoa (Theobroma cacao: Malvaceae: Malvales) is an evergreen tree native to Central America and South America. It was introduced as a crop plant into many tropical African and Asian countries for cocoa seeds which are used to make cocoa powder and chocolate [12]. It is a common tree in the rubber plantation belts as it grows well in the under storey of rubber in the region.
Sapota (Manilkara zapota: Zapotaceae: Ericales) is an evergreen tree native to Southern Mexico, Central America and the Caribbean [13]. It is grown in the front yards of residential buildings in the rubber belts for fruits as well as a shade tree.

Cassia (Cassia fistula: Fabaceae: Fabales) is a deciduous tree of deciduous forests ranging from tropical thorn to moist through subtropical thorn to moist forest zones and is a native of India. It produces yellow flowers in drooping racemes, making it an extremely showy tree in bloom with only flowers and no leaves [14]. It is a common ornamental tree in the surroundings of residential buildings as its flowers are considered as an auspicious first sight at the crack of dawn on the day of Vishu, a new year festival celebrated in the region [15]. Leaf shedding occurs during DecemberFebruary period and flowering during March-April period.

2.3. Experiment Setup. The present investigation was carried out during March 2010 using test insects and host plant leaves collected from the vicinity of a rubber plantation in the Devagiri College campus, located $6 \mathrm{~km}$ east from the Malabar Coast at Calicut $\left(11^{\circ} 15 \_\mathrm{N}, 75^{\circ} 50 \_\mathrm{E}\right)$, in the Kerala state of India.

To ensure uniformity of age at the beginning of the experiment, teneral adults were collected based on their brownish white body color [1] from rubber plantation litter in the college hostel premises. Collected beetles were reared in clay vessels placed in an environmental chamber and fed with a mixture of diced tender and mature leaves of all eight leaf types for 10 days to reduce the possible effect of leaf quality variations on growth rate and feeding preference. Beetles were deprived of food for $24 \mathrm{hrs}$ before starting the feeding experiments.

Food preferences were analyzed with multiple choice and no choice leaf disc tests in the second week of March 2010 on successive days. Tender leaves of the eight potential plants were collected from the branches of the same height during February-March 2010 and senescent leaves during November 2009 to February 2010 period. Freshly sprouted leaves of five days of age were categorized as tender and the leaves turning yellowish brown prior to the onset of annual leaf shedding as senescent. Collected leaves were kept frozen in plastic bags, and undamaged leaves were used for analysis.

Leaf discs $\left(400 \mathrm{~mm}^{2}\right)$ of each leaf type were cut and were individually marked with stapler pins (one stapler pin on leaf type 1; 2 pins parallel to each other on leaf type $2 ; 2$ pins crosswise on leaf type $3 ; 3$ pins parallel to each other on leaf type 4 , and so on) that enabled their identification. One leaf disc of each leaf type was placed inside a clay vessel $(9 \mathrm{~cm}$ diameter $\times 5 \mathrm{~cm}$ height) with a distance of $5 \mathrm{~mm}$ between the leaf discs for multiple-choice leaf disc tests, and a single leaf disc for no-choice leaf disc tests. Fifteen replicates of each experiment were conducted for tender and senescent leaves separately. In both, no-choice and multiple-choice experiments, three teneral beetles were introduced into the centre of the vessel and were allowed to feed for $24 \mathrm{hrs,}(8$ am to $8 \mathrm{am}$ ). Leaf area consumed was estimated using a $1 \mathrm{~mm}^{2}$ mesh size-reticulated paper glued on a glass slide. 
TABLE 1: Quantity $\left(\mathrm{mm}^{2}\right)$ of leaves consumed (mean $\pm \mathrm{SD}$ ) by L. tristis in multiple and no-choice experiment tests.

\begin{tabular}{lcccc}
\hline \multirow{2}{*}{ Leaf type } & No choice & Tender leaves & \multicolumn{2}{c}{ Senescent leaves } \\
& $9.60 \pm 7.84$ & Multiple choice & No choice & Multiple choice \\
\hline Cashew & $6.37 \pm 10.84$ & $1.93 \pm 2.80$ & $2.37 \pm 3.94$ & $0.31 \pm 0.51$ \\
Cassia & $76.93 \pm 56.68$ & $1.05 \pm 2.59$ & $0.92 \pm 1.50$ & $0.13 \pm 023$ \\
Cocoa & $125.33 \pm 83.61$ & $20.56 \pm 43.95$ & $4.13 \pm 5.47$ & $4.00 \pm 4.80$ \\
Jackfruit & $3.93 \pm 4.91$ & $41.66 \pm 67.32$ & $1.77 \pm 2.15$ & $0.47 \pm 0.49$ \\
Mango & $103.03 \pm 85.41$ & $0.13 \pm 0.3$ & $48.40 \pm 42.54$ & $0.38 \pm 0.47$ \\
Rubber & $0.00 \pm 0.00$ & $84.13 \pm 66.78$ & $0.00 \pm 0.00$ & $44.43 \pm 34.59$ \\
Sapota & $13.13 \pm 8.80$ & $0.00 \pm 0.00$ & $1.30 \pm 0.96$ & $0.00 \pm 0.00$ \\
Wild jack & & $6.83 \pm 5.86$ & & $0.65 \pm 0.67$ \\
\hline
\end{tabular}

TABle 2: Two-way ANOVA for feeding preference of L. tristis with respect to the leaf type and leaf age in no-choice and multiple-choice experiment tests.

\begin{tabular}{|c|c|c|c|c|c|}
\hline & \multicolumn{5}{|c|}{ No-choice } \\
\hline & SS & df & MS & $F$ & $P$ value \\
\hline Leaf type & $1,4733.44$ & 7 & 210.49 & 45.79 & $<.05$ \\
\hline Leaf age & 269.63 & 1 & 269.63 & 58.66 & $<.05$ \\
\hline Leaf type $\times$ Leaf age & 340.26 & 7 & 48.61 & 10.57 & $<.05$ \\
\hline \multirow[t]{3}{*}{ Error } & $1,029.62$ & 224.00 & 4.60 & & \\
\hline & \multicolumn{5}{|c|}{ Multiple-choice } \\
\hline & SS & df & MS & $F$ & $P$ value \\
\hline Leaf type & $1,182.14$ & 7 & 168.88 & 42.09 & $<.05$ \\
\hline Leaf age & 71.62 & 1 & 71.62 & 17.85 & $<.05$ \\
\hline Leaf type $\times$ Leaf age & 134.28 & 7 & 19.18 & 4.78 & $<.05$ \\
\hline Error & 898.73 & 224.00 & 4.01 & & \\
\hline
\end{tabular}

TABLE 3: One-way ANOVA for the quantity of tender and senescent leaves consumed by $L$. tristis in no-choice and multiple-choice experiment tests.

\begin{tabular}{lcccc}
\hline \multirow{2}{*}{ Leaf type } & \multicolumn{2}{c}{ No-choice test } & \multicolumn{2}{c}{ Multiple-choice test } \\
& $F$ & $P$ & $F$ & $P$ \\
\hline Cashew & 14.45 & 0 & 5.16 & .03 \\
Cassia & 5.15 & .03 & 7.55 & .01 \\
Cocoa & 0.4 & .53 & 2.23 & .15 \\
Jack fruit & 34.35 & 0 & 9.09 & .01 \\
Mango & 3.62 & .05 & 3.55 & .05 \\
Rubber & 3.64 & .05 & 4.45 & .04 \\
Wild jack & 46.17 & 0 & 23.33 & 0 \\
\hline
\end{tabular}

Amount of leaf disc consumed during the tests was estimated by subtracting the unconsumed area from the initial area of $400 \mathrm{~mm}^{2}$.

2.4. Data Analysis. Significance levels of the variation in the quantity of leaf consumed among the leaf types and leaf ages were assessed with two-way ANOVA and pairwise differences among leaf types with Tukey-Kramer post hoc tests ( $t$ tests). Significance level of the variation in the quantity of leaf consumed between the tender and mature leaves of each leaf type were assessed with one-way ANOVA. The preference hierarchy was reached by ranking the eight leaf types based on the significance level of the pair wise treatments for each host plant. All analyses were done following square root transformation of the data [16]. Significance was determined at $P<.05$. All statistical analyses were performed by using Minitab 16 Academic Software for windows [17].

\section{Results}

Variation in the quantity consumed by L. tristis among the eight leaf types and between the leaf ages, in both no-choice and multiple-choice experiments, was recorded (Tables 1, 2, 3 and 4).

3.1. Senescent Leaves. L. tristis consumed more senescent rubber leaves than all other leaf types in both no-choice and multiple-choice experiments (Tables 1, 4 and 5). No feeding was recorded on sapota.

\subsection{Tender Leaves}

No-Choice Experiments. Equal quantity of tender leaves of rubber and jackfruit were consumed (Tables 1, 4 and 5). Rubber and jackfruit were preferred over other six leaf types (cocoa, cashew, mango, wild jack, cassia and sapota). No feeding was recorded on sapota. 
TABLE 4: Tukey multiple comparisons ( $t$-test) of the variation in the feeding preference of $L$. tristis towards tender and senescent leaves of different leaf types in no-choice and multiple-choice experiment tests.

\begin{tabular}{|c|c|c|c|c|}
\hline \multirow{2}{*}{ Leaf types } & \multicolumn{2}{|c|}{ Tender leaves } & \multicolumn{2}{|c|}{ Senescent leaves } \\
\hline & No choice & $\begin{array}{c}\text { Multiple } \\
\text { choice }\end{array}$ & No choice & $\begin{array}{c}\text { Multiple } \\
\text { choice }\end{array}$ \\
\hline Rubber/Cashew & 0 & 0 & 0 & 0 \\
\hline Rubber/Mango & 0 & 0 & 0 & 0 \\
\hline Rubber/Jackfruit & 0.95 & 0 & 0 & 0 \\
\hline Rubber/Wild jack & 0 & 0 & 0 & 0 \\
\hline Rubber/Cocoa & 0 & 0 & 0 & 0 \\
\hline Rubber/Cassia & 0 & 0 & 0 & 0 \\
\hline Rubber/Sapota & 0 & 0 & 0 & 0 \\
\hline Cashew/Mango & 0.94 & 0.98 & 1 & 1 \\
\hline Cashew/Jackfruit & 0 & 0.01 & 0.41 & 1 \\
\hline Cashew/Wild jack & 1 & 0.84 & 1 & 1 \\
\hline Cashew/Cocoa & 0.97 & 0.34 & 0.97 & 0.2 \\
\hline Cashew/Cassia & 0.97 & 1 & 1 & 0.2 \\
\hline Cashew/Sapota & 0.08 & 0.95 & 0.56 & 0.99 \\
\hline Mango/Jackfruit & 0 & 0 & 0.37 & 1 \\
\hline Mango/Wildjack & 0.63 & 0.27 & 1 & 1 \\
\hline Mango/Cocoa & 1 & 0.04 & 0.96 & 0.25 \\
\hline Mango/Cassia & 1 & 1 & 1 & 0.25 \\
\hline Mango/Sapota & 0.65 & 1 & 0.6 & 0.99 \\
\hline Jackfruit/Wild jack & 0 & 0.33 & 0.39 & 1 \\
\hline Jackfruit/Cocoa & 0 & 0.83 & 0.95 & 0.33 \\
\hline Jackfruit/Cassia & 0 & 0 & 0.11 & 0.33 \\
\hline Jackfruit/Sapota & 0 & 0 & 0 & 0.97 \\
\hline Wild jack/Cocoa & 0.71 & 0.99 & 0.97 & 0.45 \\
\hline Wild jack/Cassia & 0.71 & 0.54 & 1 & 0.45 \\
\hline Wild jack/Sapota & 0.01 & 0.19 & 0.58 & 0.92 \\
\hline Cocoa/Cassia & 1 & 0.13 & 0.72 & 1 \\
\hline Cocoa/Sapota & 0.56 & 0.02 & 0.08 & 0.03 \\
\hline Cassia/Sapota & 0.56 & 1 & 0.92 & 0.03 \\
\hline
\end{tabular}

Multiple-Choice Experiments. More quantity of tender rubber leaves were consumed than all other seven leaf types (cashew, mango, jackfruit, wild jack, cocoa, cassia and sapota) (Tables 1, 4 and 5). Jack fruit leaves were preferred over four leaf types (cashew, mango, golden shower and sapota) and cocoa over two leaf types (mango and sapota). No feeding was recorded on sapota.

\subsection{Comparison of the Quantity of Tender and Senescent Leaves Consumed}

No-Choice Experiments. Comparison of the tender and senescent leaves consumed revealed that no difference for cocoa and sapota leaves. More tender leaves were consumed for rubber, jackfruit, cashew, mango, wild jack and cassia (Tables 1 and 3 ).
TABle 5: Preference hierarchy of L. tristis to various leaf types and leaf ages.

\begin{tabular}{lcccc}
\hline Leaf type & \multicolumn{2}{c}{ Tender } & \multicolumn{2}{c}{ Senescent } \\
Nultiple- & No-choice & $\begin{array}{c}\text { Multiple- } \\
\text { choice }\end{array}$ \\
\hline Cashew & 2 & 5 & 2 & 2 \\
Cassia & 2 & 5 & 2 & 2 \\
Cocoa & 2 & 3 & 2 & 2 \\
Jackfruit & 1 & 2 & 2 & 2 \\
Mango & 2 & 6 & 2 & 2 \\
Rubber & 1 & 1 & 1 & 1 \\
Sapota & 3 & 7 & 2 & 2 \\
Wild Jack & 2 & 4 & 2 & 2 \\
\hline
\end{tabular}

Multiple-Choice Experiments. More quantity of tender leaves of rubber, jackfruit, wild jack, cashew, mango and cassia leaves were consumed, and no difference was noticeable for cocoa and sapota (Tables 1 and 3).

\section{Discussion}

4.1. Feeding Preference towards Tender and Senescent Leaves. Preference for tender leaves of most host plants except cocoa highlights the importance of leaf age in determining the food selection and food preference of L. tristis. Reasons for the preference towards tender leaves of most host plants, preference hierarchy in its food selection and nondifferentiation of mature and tender leaves of cocoa, and non-feeding on sapota are not understood. High nutritional value could be the reason for the high preference towards tender leaves $[18,19]$. Analysis of leaf physical and chemical traits is necessary to reach conclusions. Seasonal availability of tender rubber leaves by way of leaf disease-mediated premature fall and the distinct feeding preference of $L$. tristis on tender rubber leaves is cited as the reason for the high abundance of L. tristis in rubber plantations [5], and it is expected that control of premature leaf fall may lead to decline in the population buildup of L. tristis in rubber plantation belts. However, feeding on the tender leaves of other trees common in rubber plantation belts indicates that $L$. tristis has alternate leaf resources in the absence of rubber leaves. Analysis of reproductive performance of L. tristis on alternate host plants, survival experiments, oviposition, and larval feeding preferences are necessary to reach conclusions about the implications of present findings. Among the various alternate host plants, feeding pattern on cocoa requires special attention. In addition to the equal preference of $L$. tristis towards its mature and tender leaves, periodical pruning off tender shoots by the farmers leads to frequent tender leaf availability in cocoa plantations. How tender leaf availability of cocoa facilitates the population buildup of $L$. tristis needs to be ascertained. Spotting of $L$. tristis in cocoa plantations, equal preference towards tender and mature cocoa leaves and presence of patches of cocoa plantations and the scarce distribution of other host plants in rubber belts leads to the proposal that in the absence of 


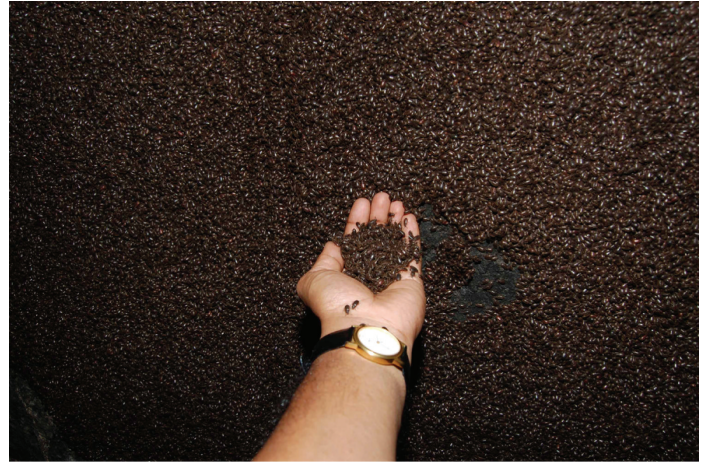

Figure 1: Aggregated beetles on the wall of a residential building.

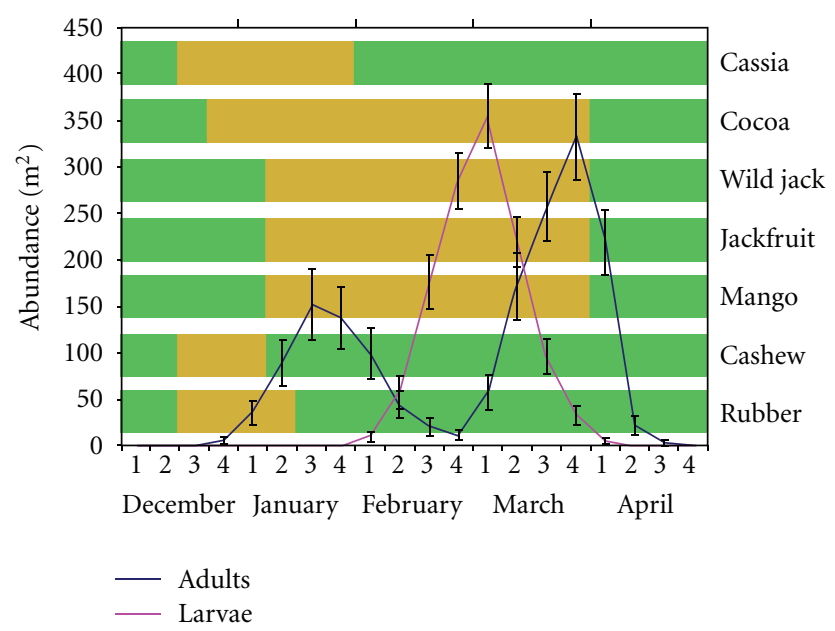

FIGURE 2: Foliage phenology of the host plants and population buildup of $L$. tristis in litter habitat during post-rainy breeding and feeding period (abundance data of L. tristis based on [2]; yellow colour depicts peak leaf fall period of evergreen plants and annual leaf shedding period of deciduous plants; blue coloured line depicts adults and pink coloured line larvae).

tender and mature rubber leaves, cocoa becomes the major host plant of $L$. tristis more than other host plants.

4.2. Host Plants of L. tristis and Implications. First experimental confirmation that Luprops tristis is a generalist and not a specialist on rubber and that it has distinct preference hierarchy in its food selection with rubber becoming the most preferred host plant species followed by jackfruit and cocoa is reached at. It raises the question whether showing inclination to feed up on three plants is enough to consider the beetle as a generalist? However, record of L. tristis in nonrubber belts in South East India before the introduction of rubber plantations in the moist south west India [20-22] indicates that rubber is not the sole host plant or ancestral host plant of L. tristis.

Selection of jackfruit and cocoa as the second most preferred food choice indicates that rubber plantation littercentered efforts to control $L$. tristis such as premature leaf fall prevention in rubber plantations alone may not be effective as L. tristis may switch over to alternate host plants. Presence of $L$. tristis in the litter stands of cocoa, jackfruit, wild jack, cashew, mango and cassia (first author, personal observations) indicates that postdormancy beetles that arise from the 8-9 month long dormancy with the onset of post monsoon dry conditions ([2]; Figure 2) might be taking a transitory shelter and sustain on the tender and senescent leaves of cocoa and tender leaves of other host plants till annual litter fall followed by premature leaf fall occurs in rubber plantations.

Based on the host plant selection behavior of polyphagous insects $[19,23]$ and the phenology of $L$. tristis in rubber belts [5], preference towards rubber is attributed to two possibilities. Rubber is the most high-quality host plant species among the listed host plants. Feeding on other leaf types, even when rubber leaves were available during multiple-choice tests, logically raises question about the possible reasons for feeding on mixed diets and the advantages it provides. These observations reiterate the need for survival experiments and analysis of reproductive performance of $L$. tristis on each one of these host plants to reach conclusions. Secondly, literature on host plant selection of phytophagous insects revealed that concentrating on a particular species enables information about the environment to be processed more efficiently, increases the rate of host plant location/utilization [24-28], processes more information about that species by the females, and detects the variation in the quality of individual plants more efficiently [19, 29]. However, with overspecialization of L. tristis on the seasonally available leaves of the deciduous host plant, rubber would have affected its survival chances whereas generalist feeding behavior provides access to a greater resource base, a more nutritionally balanced diet $[18,30-32]$. Hence, feeding on mixed diets of different evergreen host plants (generalist feeding behavior) may be an adaptive strategy of $L$. tristis to avoid overspecialization on a deciduous host plant (rubber) with highly seasonal leaf shedding behavior. However, evidence from plant-feeding insects showed that early experience in feeding on one type of resource may make it easier to exploit the same resource later in life or influence host choices later in development [33-35]. Hence, it is possible that the high degree of preference expressed for rubber could partly reflect pre-experiment feeding on this plant and associated induction of host preferences.

4.3. Predictions. High preference of $L$. tristis towards rubber leaves, presence of alternate host plants in rubber belts and earlier data on its wide prevalence in rubber plantations, high reproductive potential of $L$. tristis, and the possession of defensive gland secretions that deters the natural predators in litter habitat and aggregation sites [36,37] indicate that prospects of further increase of $L$. tristis across the rubber belts is a certainty. Although $L$. tristis is recorded from Sri Lanka, South India, and Nepal [22], it is not recorded as a nuisance pest in these regions. Selection of rubber followed by jackfruit and cocoa as the most favored host plant and non-differentiation between tender and mature cocoa leaves indicates that $L$. tristis has high potential to 
become a nuisance pest in the new rubber plantation belts coming up in non-traditional rubber belts in the Indian subcontinent as well as in the cocoa plantation belts in South India.

4.4. Implications for Pest Management. Findings from the study have important bearing on the pest management strategies to be adopted for L. tristis.

(1) Present study establishes that L. tristis is a generalist feeder and not a specialist on rubber, and it has distinct preference hierarchy in its food selection with rubber becoming the most preferred host plant species followed by jackfruit and cocoa.

(2) Selection of jackfruit and cocoa as the preferred food choice after rubber, and its feeding on alternate host plants indicates that field stands-based efforts for control of $L$. tristis should consider the leaf litter accumulated around the alternate host plants.

(3) Non-differentiation of tender and mature cocoa leaves, shows that in the absence of rubber leaves cocoa plants become the major host plant of $L$. tristis than the less abundant jackfruit trees whose fallen tender leaves may not be available in sufficient quantity. Hence, it is likely that availability of cocoa litter might have contributed towards population build up of $L$. tristis in regions where intercropping of cocoa and rubber is practiced.

\section{Acknowledgments}

Financial assistance provided by Kerala State Council for Science Technology and Environment (KSCSTE), Government of Kerala is gratefully acknowledged. The authors are grateful to Thomachan K.T. (St. Joseph's College, Devagiri, Calicut) for statistical support, Helen F. Nahrung (Department of Primary Industries \& Fisheries, Queensland, Australia) for critical comments, and Nirdev P. M. and Shiju T. Raj (St. Joseph's College, Devagiri, Calicut) for logical assistance.

\section{References}

[1] T. K. Sabu, K. V. Vinod, and M. C. Jobi, "Life history, aggregation and dormancy of the rubber plantation litter beetle, Luprops tristis, from the rubber plantations of moist south Western Ghats," Journal of Insect Science, vol. 8, article 1, 2008.

[2] T. K. Sabu and K. V. Vinod, "Population dynamics of the rubber plantation litter beetle Luprops tristis, in relation to annual cycle of foliage phenology of its host, the para rubber tree, Hevea brasiliensis," Journal of Insect Science, vol. 9, article 56, pp. 1-10, 2009.

[3] K. T. Sabu, "Litter insect dynamics with special reference to ecological succession and chemical ecology along varying altitudes in the Wynad and Coorg forests of Western Ghats," Project Report, submitted to Ministry of Environment and Forests. Government of India, 2005.

[4] P. J. Vineesh, cology and diversity of Entomofauna in the litter stands of monoculture and natural forests in Kannur district, Ph.D dissertation, University of Calicut, Kerala, India, 2007.
[5] T. K. Sabu and K. V. Vinod, "Food preferences of the rubber plantation litter beetle, Luprops tristis, a nuisance pest in rubber tree plantations," Journal of Insect Science, vol. 9, article 72, 2009.

[6] K. T. Kurian and A. O. N. Panikkar, "Indian rubber plantation industry: genesis and development," in Natural Rubber: Agromanagement and Crop Processing, P. J. George and C. K. Jacob, Eds., pp. 1-19, Rubber Research Institute of India, Kottayam, India, 2000.

[7] I. S. E. Bally, "Mangifera indica (mango), ver. 3.1," in Species Profiles for Pacific Island Agroforestry, C. R. Elevitch, Ed., Permanent Agriculture Resources (PAR), Hōlualoa, Hawaii, USA, 2010.

[8] R. Nadgauda, S. Jayasankar, and R. E. Litz, "Anacardium occidentale Cashew," in Biotechnology of Fruit and Nut Crops, R. E. Litz, Ed., CABI Publishing, UK, 2005.

[9] E. V. V. B. Rao, K. R. M. Swamy, and M. G. Bhat, "Status of cashew breeding and future priorities," Journal of Plantation Crops, vol. 26, pp. 103-114, 1998.

[10] C. R. Elevitch and H. I. Manner, "Artocarpus heterophyllus (jackfruit), ver. 1.1v.," in Species Profiles for Pacific Island Agroforestry, C. R. Elevitch, Ed., Permanent Agriculture Resources (PAR), Hōlualoa, Hawaii, USA, 2010.

[11] B. R. Ramesh, J. P. Pascal, and C. Nouguier, Atlas of Endemics of the Western Ghats (India): distribution of Tree Species in the Evergreen and Semi-evergreen Forests, vol. 38 of Publications $d u$ Departement d' Ecologie, Institut Francais de Pondichery, 1997.

[12] M. Frankis and K. Schulz, "Theobroma cacao L.," Encyclopedia of Life, 2010, http://www.eol.org/pages/484592.

[13] J. Morton, "Sapodilla. p.," in Fruits of Warm Climates, J. F. Morton and F. L. Miami, Eds., 1987, http://en.wikipedia.org/ wiki/Manilkarazapota.

[14] C. Orwa, A. Mutua, R. Kindt, R. Jamnadass, and A. Simons, "Agroforestry Database: a tree reference and selection guide version 4.0," 2009, http://www.worldagroforestry.org/af/ treedb.

[15] Database on State of Environment, Kerala, "Kerala Symbols," 2008, http://www.kerenvis.nic.in/isbeid/kerala-symbols.htm.

[16] N. A. Weiss, Introductory Statistics, Dorling Kindersley, India, 7th edition, 2007.

[17] Minitab Inc., MINITAB Statistical Software, Release 16 for Windows, 2010.

[18] E. A. Bernays and R. F. Chapman, Host-Plant Selection by Phytophagous Insects, Chapman \& Hall, New York, NY, USA, 1994.

[19] S. A. West and J. Paul Cunningham, "A general model for host plant selection in phytophagous insects," Journal of Theoretical Biology, vol. 214, no. 3, pp. 499-513, 2002.

[20] L. Fairmaire, "Hétéromères de l'Inde recueillis par M. Andrewes," Annales de la Société Entomologique de Belgique, vol. 40, pp. 6-62, 1896.

[21] Z. Kaszab, “Tenebrioniden aus Südindien (Coleoptera)," Acta Zoologica Academiae Scientiarum Hungaricae, vol. 25, no. 3-4, pp. 259-310, 1979.

[22] T. K. Sabu, O. Merkl, and P. Abhitha, "A new Luprops species from Western Ghats with redescriptions and identification key to the species of Indian Peninsula and Sri Lanka (Tenebrionidae: Lagriinae: Lupropini)," Zootaxa, no. 1636, pp. 47-58, 2007.

[23] T. Jermy, "The role of experience in the host selection of phytophagous insects," in Perspectives in Chemoreception and Behavior, R. F. Chapman, E. A. Bernays, and J. G. Stoffolano, Eds., pp. 143-157, Springer, New York, NY, USA, 1987. 
[24] R. Dukas and C. W. Clark, "Searching for cryptic prey: a dynamic model," Ecology, vol. 76, no. 4, pp. 1320-1326, 1995.

[25] S. R. X. Dall and I. C. Cuthill, "The information costs of generalism," Oikos, vol. 80, no. 1, pp. 197-202, 1997.

[26] E. A. Bernays, "The value of being a resource specialist: behavioral support for a neural hypothesis," American Naturalist, vol. 151, no. 5, pp. 451-464, 1998.

[27] J. P. Cunningham, M. F. A. Jallow, D. J. Wright, and M. P. Zalucki, "Learning in host selection in Helicoverpa armigera (Hubner) (Lepidoptera: Noctuidae)," Animal Behaviour, vol. 55, no. 1, pp. 227-234, 1998.

[28] E. A. Bernays and D. J. Funk, "Specialists make faster decisions than generalists: experiments with aphids," Proceedings of the Royal Society B: Biological Sciences, vol. 266, no. 1415, pp. 151156, 1999.

[29] N. Janz and S. Nylin, "The role of female search behaviour in determining host plant range in plant feeding insects: a test of the information processing hypothesis," Proceedings of the Royal Society B: Biological Sciences, vol. 264, no. 1382, pp. 701707, 1997.

[30] E. A. Bernays and O. P. J. M. Minkenberg, "Insect herbivores: different reasons for being a generalist," Ecology, vol. 78, no. 4, pp. 1157-1169, 1997.

[31] D. J. Funk and E. A. Bernays, "Geographic variation in host specificity reveals host range evolution in Uroleucon ambrosiae aphids," Ecology, vol. 82, no. 3, pp. 726-739, 2001.

[32] S. P. Egan and D. J. Funk, "Individual advantages to ecological specialization: insights on cognitive constraints from three conspecific taxa," Proceedings of the Royal Society B: Biological Sciences, vol. 273, no. 1588, pp. 843-848, 2006.

[33] D. N. Karowe, "Facultative monophagy as a consequence of prior feeding experience-behavioral and physiological specialization in Colias philodice larvae," Oecologia, vol. 78, no. 1, pp. 106-111, 1989.

[34] K. E. Ward, S. B. Ramaswamy, and T. E. Nebeker, "Feeding preferences and their modification in early and late instar larvae of the bagworm, Thyridopteryx ephemeraeformis (Lepidoptera: Psychidae)," Journal of Insect Behavior, vol. 3, no. 6, pp. 785-795, 1990.

[35] J. P. Cunningham, M. P. Zalucki, and S. A. West, "Learning in Helicoverpa armigera (Lepidoptera: Noctuidae): a new look at the behaviour and control of a polyphagous pest," Bulletin of Entomological Research, vol. 89, no. 3, pp. 201-207, 1999.

[36] P. Abitha, Forest Litter faunal diversity and abundance in relation to litter chemical quality and systematics of Carabid beetles, Ph.D dissertation, Forest Research University, Dehradun, India, 2009.

[37] P. Aswathi and T. K. Sabu, "Weaver ant (Oecophylla smaragdina), huntsman spider (Heteropoda venatoria) and house gecko (Hemidactylus frenatus) as potential biocontrol agents of the nuisance pest, Luprops tristis," Halteres, vol. 3, no. 3, pp. 56-61, 2011. 

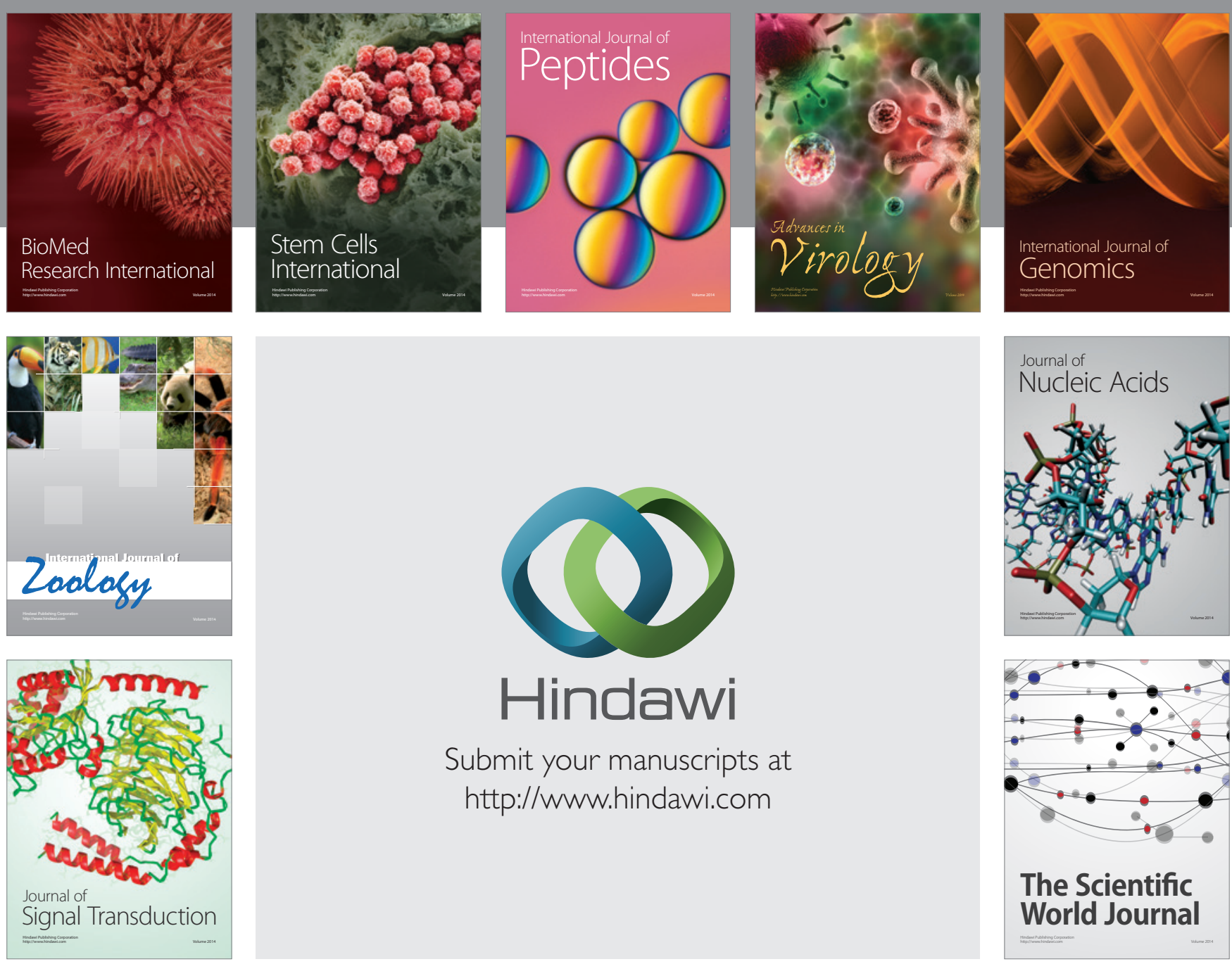

Submit your manuscripts at

http://www.hindawi.com
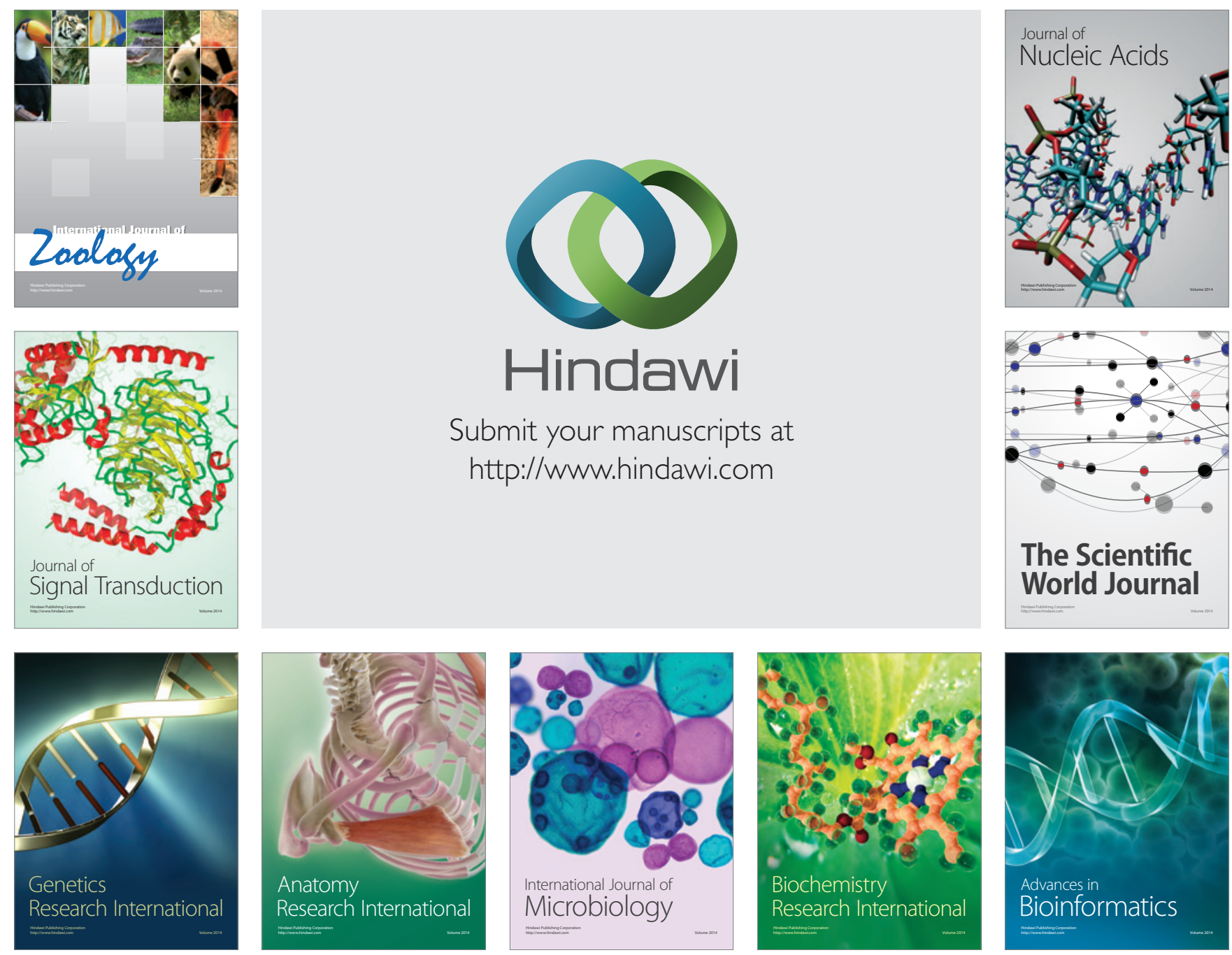

The Scientific World Journal
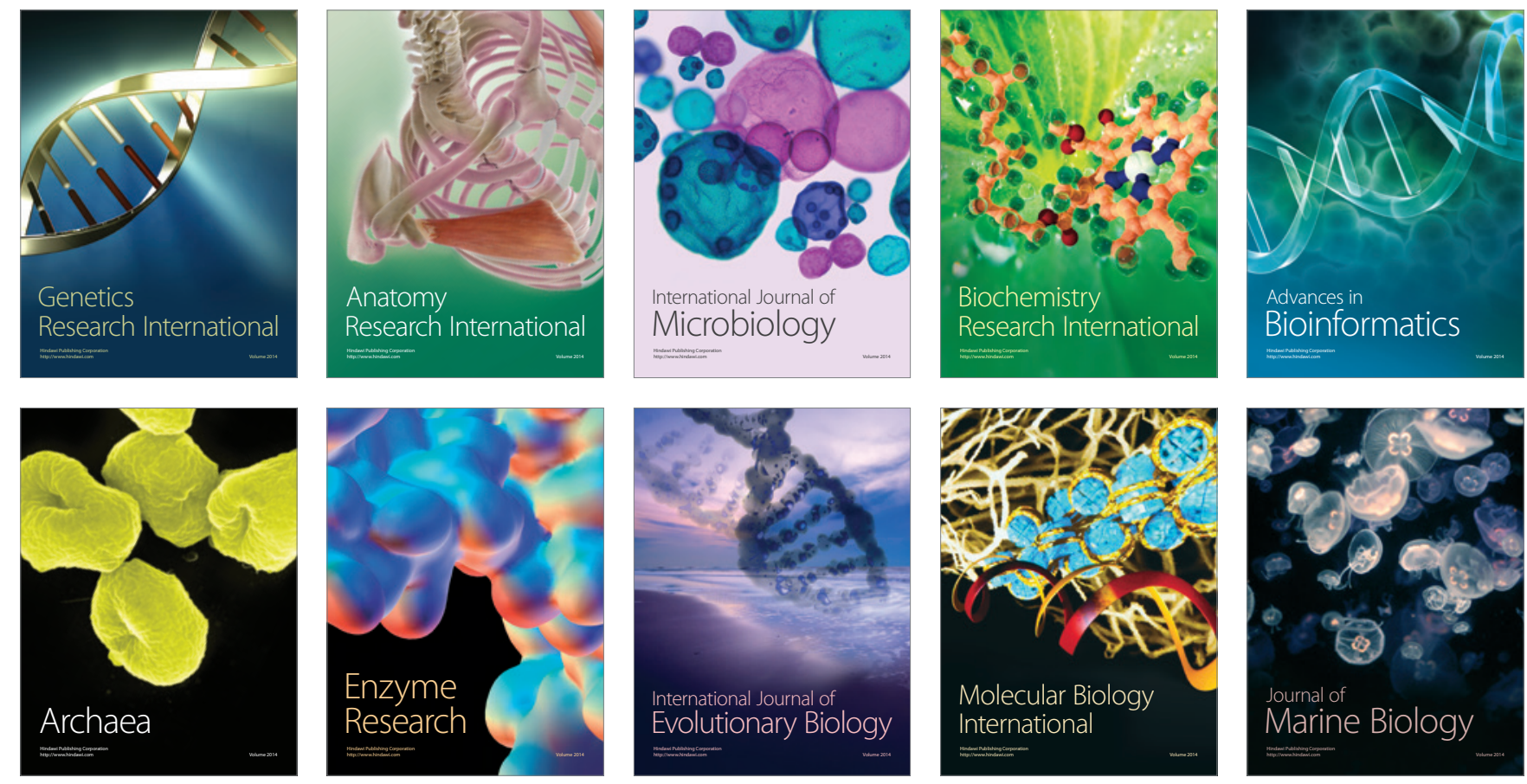